\title{
A formação de professores no Pibid: novas práticas, novos desafios
}

\author{
The formation of the teachers at Pibid: new practices, new challenges
}

\author{
Liliane Silva de Antiqueira* \\ Celiane Costa Machado ${ }^{* *}$ \\ Elaine Corrêa Pereira**
}

\section{Resumo}

Este artigo busca refletir sobre como é desenvolvida a proposta de formação do Programa Institucional de Bolsas de Iniciação à Docência (Pibid) na Universidade Federal do Rio Grande (Furg). Para o aporte teórico, utilizam-se as ideias de Diniz-Pereira (2008), que defende a articulação entre universidade e escola para o preparo de novos profissionais da educação, num movimento de formação acadêmico-profissional, Galiazzi e Moraes (2013) e Brandão (2005), os quais acreditam numa proposta de formação de professores com base em comunidades aprendentes. Além disso, são abordadas características do programa e um panorama do seu desenvolvimento na Furg. Apresenta-se um recorte dos subprojetos Matemática e Interdisciplinar e como suas ações contribuem na formação de professores e licenciandos. Conclui-se que tanto a universidade quanto a escola e a comunidade são contempladas por impactos positivos do Pibid, o qual colabora para promover uma formação acadêmico-profissional por meio da ação-reflexão-ação, articulando teoria e prática desde a sala de aula até os cursos de licenciaturas.

Palavras-chave: Formação acadêmico-profissional. Comunidades aprendentes. Formação de professores. Pibid.

\section{Abstract}

This essay has as its goal the reflection about how is developed the proposal that refers to the formation of the Institutional Program of the Initiation of Teaching Scholarship (Pibid) at the University Federal of Rio Grande (Furg). For the theoretical support, it is used the ideas of Diniz-Pereira (2008) that defend the articulation between the university and the school in order to prepare new educational professionals in an academic-professional of formation movement, Galiazzi and Moraes (2013) and Brandão (2015) that believe in a teaching formation proposal based on learning communities. Furthermore, it is mentioned the characteristics of the program and an overview of its development at Furg. It is also presented a fraction of the subprojects Mathematics and Interdisciplinary and how their actions contribute for the formation of the teachers and undergraduated students. Hence, not only the university but also the school and the community, are achieved by the positive impacts of Pibid, which collaborates to promote academic and vocational training through action-reflection-action, linking theory and practice from the room class to the undergraduate courses.

Keywords: Academic-professional. Learning communities. Teaching formation. Pibid.

Recebido em 23/03/2018 - Aprovado em 30/10/2018

http://dx.doi.org/10.5335/rep.v26i2.5949

Doutora em Educação em Ciências pela Universidade Federal do Rio Grande. Formação em Matemática Licenciatura pela Universidade Federal do Rio Grande e em Pedagogia pela Universidade Luterana do Brasil, Brasil. E-mail: Iilianeantiqueira@furg.br

** Doutora em Matemática Aplicada pela Universidade Federal do Rio Grande do Sul. Professora adjunta do Instituto de Matemática, Estatística e Física da Furg, Brasil. E-mail: celianecmachado@yahoo.com.br

*** Pós-doutora pela Universidade Eduardo Mondlane, Moçambique. Professora adjunta do Instituto de Matemática, Estatística e Física da Universidade Federal do Rio Grande, Brasil. E-mail: elainepereira@prolic.furg.br 


\section{Introdução}

A temática referente à formação de professores é apresentada como destaque em vários cenários. Atualmente, a ênfase é em atribuir aos professores a função de agentes das mudanças requeridas pela nova ordem mundial emergente. Além disso, os próprios professores mostram a premência por ações de formação que deem conta de atender às reais necessidades da escola (LIMA; GOMES, 2012).

Ao encontro dessas ações de formação, tem-se o Programa Institucional de Bolsas de Iniciação à Docência (Pibid), com o objetivo de possibilitar aos alunos de licenciaturas e professores da educação básica experiências metodológicas e práticas docentes de caráter inovador e interdisciplinar. Sobre a proposta desse programa, Bernardes e Diniz-Pereira (2012, p. 253) entendem o processo de iniciação à docência como um "[...] importante momento da formação do professor, no qual ele se insere no meio onde desenvolverá suas atividades, passando a se constituir e ser (auto)reconhecido como profissional".

Surge, então, a necessidade de articular universidade e escola, para que, juntas, preparem novos profissionais da educação, num movimento de formação acadêmico-profissional (DINIZ-PEREIRA, 2008). Assim, acredita-se que a formação docente tem seu início antes de o aluno ingressar na licenciatura, uma vez que a formação perpassa todo o período escolar e se dá também no decorrer da prática profissional, o que torna a escola espaço-tempo de formação e não somente um local de trabalho. Por esta razão, neste texto, utiliza-se o termo formação acadêmico-profissional no lugar de formação inicial e continuada, por entender que, segundo Diniz-Pereira (2011, p. 213), existe uma "[...] ligação entre as instituições universitárias de formação e as escolas da educação básica”, que vai além da licenciatura e do trabalho docente.

Diante disso, Araújo e Moura (2012, p. 77) ressaltam que os termos formação inicial e continuada "[...] trazem em si limitações, uma vez que procuram representar uma ruptura que consideramos não existir”. Para Diniz-Pereira (2008, p. 265), o termo formação inicial é:

[...] acriticamente adotado pela literatura especializada - que carrega consigo a ideia de uma preparação que se inicia a partir da entrada do futuro professor em um programa de formação docente, desconhecendo, dessa maneira, momentos e experiências anteriores importantíssimos nesse processo de formação. 
Outro aspecto importante para se pensar a formação de professores é compreender o conceito de comunidades aprendentes proposto por Brandão (2005). O autor elucida a ideia de que:

[...] a menor unidade do aprender não é cada pessoa, cada aluno, cada estudante tomado em sua individualidade. Ela é o grupo que se reúne frente à tarefa partilhada de criar solidariamente seus saberes. É a pequena comunidade aprendente, através da qual cada participante ativo vive o seu aprendizado pessoal (BRANDÃO, 2005, p. 89, grifo do autor).

É o coletivo em busca do ensinar e aprender, em busca do ouvir, falar, dialogar, partilhar. No âmbito do contexto educacional, Galiazzi e Moraes (2013, p. 265) contribuem com essa reflexão ao afirmarem que "[...] comunidades aprendentes de professores constituem espaços de formação qualificada para todos os que neles se envolvem efetivamente". Então, pode-se entender que o Pibid é uma comunidade aprendente, na qual todos se engajam em torno das atividades, uma comunidade em que "[...] estamos sempre, de um modo ou de outro, trabalhando em, convivendo com ou participando de unidades sociais de vida cotidiana onde pessoas aprendem ensinando e ensinam aprendendo" (BRANDÃO, 2005, p. 88, grifo do autor).

A partir dessas compreensões, busca-se refletir sobre o desenvolvimento da proposta de formação do Pibid da Universidade Federal do Rio Grande (Furg), com ênfase em algumas atividades desenvolvidas no decorrer do Edital 61/2013. Para isso, são abordadas as características gerais do programa e um panorama do seu desenvolvimento desde sua primeira edição nessa universidade. Na sequência, são apresentadas algumas atividades dos subprojetos Matemática e Interdisciplinar, referentes aos anos de 2014 e 2015, e como suas ações contribuem na formação de professores e licenciandos. Ao final, apresenta-se as conclusões obtidas.

\section{Formação de professores na perspectiva do Pibid}

O Pibid está inserido em uma matriz educacional que articula três importantes vertentes: produção de conhecimento, formação de qualidade e integração entre pós-graduação, formação de professores e educação básica (COORDENAÇÃO DE APERFEIÇOAMENTO DE PESSOAL DE NÍVEL SUPERIOR, 2011). Trata-se de uma proposta para melhorar a qualidade da formação de professores nos cursos de licenciatura, promovendo ações e intenso diálogo entre a instituição de ensino superior (IES) e as escolas da rede pública, buscando, dessa forma, inserir os licenciandos no contexto escolar desde o início da formação acadêmica. 
Após a inserção, os licenciandos planejam e desenvolvem atividades didático-pedagógicas sob a orientação do professor vinculado a uma licenciatura da IES e de um professor atuante na escola, o qual recebe o nome de supervisor. Esse entrosamento é muito significativo na formação de ambos, na medida em que trabalham juntos e refletem sobre essas experiências. É uma iniciação à docência, estando presente no espaço escolar. Além disso, os alunos da educação básica são contemplados com atividades que os auxiliam na aprendizagem e na sua formação. Esse trabalho coletivo está evidenciado nas palavras de Galiazzi e Moraes (GALIAZZI; MORAES, 2013, p. 266), ao afirmarem que:

Em comunidades aprendentes de formação de professores o foco está num processo sistemático, voltado para atingir determinados objetivos, especialmente havendo um esforço coletivo para melhorar resultados individuais e coletivos de aprendizagem de todos os participantes.

Desse processo de formação, emerge o entrelaçamento entre teoria e prática, pois o licenciando vivencia o cotidiano da escola e se percebe professor, atuando diretamente na sala de aula, diante de situações e desafios do contexto escolar. No entanto, ele não assume a função do professor, nem realiza outras atividades administrativas na escola.

Remetendo aos objetivos pedagógicos do Pibid, o relatório de gestão (COORDENAÇÃO DE APERFEIÇOAMENTO DE PESSOAL DE NÍVEL SUPERIOR, 2013b, p. 69) afirma que o programa "[...] é pautado em pressupostos teórico-metodológicos que articulam teoria-prática, universidade-escola e formadores-formandos". Essa interação enriquece o processo formativo da docência com a finalidade "[...] de aperfeiçoar os elementos teórico-práticos para o magistério e possibilitar que o trabalho dos futuros professores seja mobilizado pela ação-reflexão-ação" (COORDENAÇÃO DE APERFEIÇOAMENTO DE PESSOAL DE NÍVEL SUPERIOR, 2013b, p. 70).

É nesse sentido que Diniz-Pereira (2008) defende a parceria entre universidade e escola para a formação de professores da educação básica, ou seja, ações conjuntas com propósitos comuns. "Essas duas instituições, universidades e escolas, deveriam compartilhar responsabilidades em termos da complexa tarefa de preparar novos profissionais da educação" (DINIZ-PEREIRA, 2008, p. 1).

Diante dessa dinamicidade estabelecida entre o Pibid e o processo formativo dos professores, Barbosa e Dantas (2014, p. 18) reforçam que esse programa “[...] possui os elementos necessários para criar as condições para uma formação inicial consistente, articulada e que realmente seja fruto do diálogo entre universidade e escola". 
Nesse viés, Rocha e Zibetti (2014, p. 149) acrescentam que “[...] a integração entre IES e escola básica, a formação por meio de bolsas e a dicotomia entre teoria e prática, de modo geral, apontam o PIBID como uma política educacional compensatória”.

No que concerne à ideia de iniciação à docência, Reichert, Moana e Lima (2014, p. 15) consideram que “[...] essa formação se faz por um estar lá, mas, mais do que isso, é por um estar dentro: o bolsista mergulha nessa realidade, encharca-se dela... É o seu olho que vê. Essa experiência não é possível ter quando se olha do exterior". Ao encontro dessas constatações, alguns dos princípios norteadores do programa são:

I - Incentivar a formação de docentes em nível superior para a educação básica; II - Contribuir para a valorização do magistério; III - Inserir os licenciandos no cotidiano de escolas da rede pública de educação, proporcionando-lhes oportunidades de criação e participação em experiências metodológicas, tecnológicas e práticas docentes de caráter inovador e interdisciplinar que busquem a superação de problemas identificados no processo de ensino aprendizagem; IV - Incentivar escolas públicas de educação básica, mobilizando seus professores como coformadores dos futuros docentes e tornando-as protagonistas nos processos de formação inicial para o magistério; V - Contribuir para a articulação entre teoria e prática necessárias à formação dos docentes, elevando a qualidade das ações acadêmicas nos cursos de licenciatura (COORDENAÇÃO DE APERFEIÇOAMENTO DE PESSOAL DE NÍVEL SUPERIOR, 2013b, p. 70).

Tais princípios regulamentaram os seis editais lançados, desde 2007 até 2013. O primeiro foi para atender às demandas de formação nas áreas de Física, Química, Biologia e Matemática, devido à carência de professores nessas disciplinas. Nos editais posteriores, houve uma progressiva expansão do programa, passando a englobar todas as áreas do conhecimento e um número expressivo de IES (BARBOSA; DANTAS, 2014). Cabe destacar que, em 2018, ano de conclusão do sexto edital, a Coordenação de Aperfeiçoamento de Pessoal de Nível Superior (Capes) lançou o Edital 07/2018, visando à continuidade do Pibid por um período de dezoito meses.

Gatti et al. (2014, p. 106) sinalizam que o Pibid como política pública contribui para a "[...] valorização da profissão de professor, [...], é um programa que desacomoda as licenciaturas e mobiliza escolas. Por suas contribuições deve ser institucionalizada e tornada perene como política de Estado". Os autores também mencionam outras contribuições do programa, entre elas: colabora para a permanência dos estudantes nas licenciaturas e para a redução da evasão; estimula a iniciativa e a criatividade, incentivando os licenciandos a planejar e desenvolver atividades de ensino e a construir diferentes materiais didáticos e pedagógicos; aproxima o professor supervisor do meio acadêmico, ajudando a articular o conhecimento acadêmico com o conhecimento da prática em uma perspectiva formativa; 
ajuda a questionar construtivamente a qualidade das práticas formativas no âmbito da docência na própria IES (GATTI et al., 2014).

No que se refere às escolas e aos alunos da educação básica, o Pibid, por meio de suas ações, possibilita melhorias na qualidade do ensino, com novas maneiras de ensinar, aulas mais criativas, com atividades práticas diferenciadas e interdisciplinares, além da ativação ou do uso frequente de laboratórios e melhor uso da biblioteca (GATTI et al., 2014). Ademais, o Pibid tem incentivado a formação acadêmico-profissional docente e contribuído para o contato dos estudantes com o cotidiano escolar da educação básica, o que vai ao encontro dos objetivos propostos pelo programa.

Coerente com as informações e reflexões apresentadas, entende-se o Pibid como um espaço de formação acadêmico-profissional que corrobora, diretamente, com a formação do professor e com a sala de aula da educação básica, principalmente por possibilitar a integração entre escola e universidade. Várias ações são desenvolvidas nas diversas universidades do país, e, com isso, novos desafios são postos aos integrantes. A seguir, é apresentada a proposta de formação do Pibid/ Furg, com ênfase na participação da universidade no Edital 61/2013.

\section{A formação acadêmico-profissional do Pibid/Furg na perspectiva de uma comunidade aprendente}

A Furg é uma das IES participantes do Pibid e possui como princípio teórico a compreensão de que o professor se forma e aprende a gostar de ser professor na atividade com outros professores (COLARES, 2013). A proposta institucional tem como fundamento as comunidades aprendentes de professores, definidas por Galiazzi e Moraes (2013, p. 264) como "[...] grupos de pessoas em torno de atividades articuladas por objetivos comuns que têm foco na linguagem e nos discursos específicos de diferentes campos de conhecimento". Entende-se que "[...] essas atividades são especialmente a produção textual em que os participantes se envolvem na reconstrução do conhecimento existente e expresso por todos e de certa forma da própria comunidade" (GALIAZZI; MORAES, 2013, p. 264).

O termo aprendente deriva da aventura interior e pessoal que é o aprender, baseado nos momentos de aprendizagem que são resultantes da convivência em e entre diferentes grupos, além das relações de partilha e de interações estabelecidas com outras pessoas. Isso acontece nos mais diversos contextos sociais e lugares, nos quais um grupo, contendo pessoas com objetivos comuns, ensinam e apren- 
dem mutuamente. Assim, tem-se a constituição de diferentes tipos de comunidades aprendentes, de modo que todos aprendem juntos (BRANDÃO, 2005).

É com esse olhar que o Pibid/Furg forma uma comunidade aprendente, na qual os integrantes se engajam em torno das atividades. Trata-se de "[...] uma nova concepção do viver como partilhar experiências, saberes e sensibilidades em situações e contexto regidos cada vez mais pela partilha, pela cooperação, pela solidariedade, pela gratuidade" (BRANDÃO, 2005, p. 91). Esse movimento de partilha está presente na formação que o programa possibilitou a todos seus participantes, por meio de ações que permearam os diferentes subprojetos.

Nessa perspectiva, Galiazzi et al. (2013) consideram que as comunidades não surgem prontas, aprendem a ser comunidades aprendentes ao longo de sua existência, na medida em que as aprendizagens se ampliam e os relacionamentos e as compreensões se intensificam. Assim, o Pibid/Furg é um espaço de aprendizagem para todos os envolvidos, com intensa interação nas ações desenvolvidas, em que todos ensinam e aprendem coletivamente.

Com esse foco, a universidade participou dos editais lançados pela Capes, cujas propostas foram elaboradas a partir da compreensão de que a docência não se dá no isolamento, mas na interação entre os pares (GALIAZZI; COLARES, 2013). A Tabela 1 mostra a participação do Pibid/Furg e a inserção dos cursos relacionados às licenciaturas.

Tabela 1 - Desenvolvimento do Pibid/Furg

\begin{tabular}{|c|c|c|c|c|}
\hline Editais & Vigência & Subprojetos & $\begin{array}{l}\text { Número de } \\
\text { licenciandos }\end{array}$ & $\begin{array}{l}\text { Número de } \\
\text { supervisores }\end{array}$ \\
\hline $1 / 2007$ & $\begin{array}{l}\text { Mar. } 2009 \text { a } \\
\text { Dez. } 2010\end{array}$ & Matemática, Física, Biologia e Química & 63 & 14 \\
\hline 2/2009 & $\begin{array}{l}\text { Mar. } 2010 \text { a } \\
\text { Jan. } 2012\end{array}$ & $\begin{array}{l}\text { Artes, Letras/Inglês, Letras/Português, Pedagogia, Le- } \\
\text { tras/Espanhol e História }\end{array}$ & 79 & 14 \\
\hline $1 / 2011$ & $\begin{array}{l}\text { Jul. } 2011 \text { a } \\
\text { Fev. } 2014\end{array}$ & $\begin{array}{l}\text { Matemática, Física, Biologia, Química e novos subproje- } \\
\text { tos Educação Física, Geografia e Letras/Francês }\end{array}$ & 116 & 22 \\
\hline $11 / 2012$ & $\begin{array}{l}\text { Ago. } 2012 \\
\text { a Fev. } 2014\end{array}$ & $\begin{array}{l}\text { Letras/Inglês, Letras/Português, Pedagogia, Letras/Es- } \\
\text { panhol, Artes e História, e novos subprojetos Gestão } \\
\text { Escolar e Educação Ambiental }\end{array}$ & 160 & 22 \\
\hline $61 / 2013$ & $\begin{array}{l}\text { Mar. } 2014 \text { a } \\
\text { Fev. } 2018\end{array}$ & $\begin{array}{l}\text { Matemática, Física, Biologia, Química, Educação Física, } \\
\text { Geografia, Letras/Francês, Letras/Inglês, Letras/Portu- } \\
\text { guês, Pedagogia, Letras/Espanhol, Interdisciplinar, Histó- } \\
\text { ria, Artes, Ciências/EaD e Letras/Espanhol/EaD }\end{array}$ & 265 & 46 \\
\hline
\end{tabular}

Fonte: elaboração dos autores a partir de Galiazzi e Colares (2013). 
Conforme consta na Tabela 1, por meio do Edital 1/2007, houve o desenvolvimento da primeira edição do Pibid na Furg, atendendo quatro cursos de licenciaturas, isso se deve pela carência de profissionais nas respectivas áreas. Foram 14 professores supervisores da rede pública de ensino e mais de 60 licenciandos que realizaram experiências metodológicas de acordo com o contexto escolar do município onde se situa a instituição.

No Edital 2/2009, as áreas de formação foram ampliadas e a universidade participou com a proposta denominada de "Práticas Educativas na Educação Básica: diálogos em roda na formação de (futuros) professores na Furg”. A Tabela 1 mostra as 6 licenciaturas contempladas, totalizando 14 professores supervisores e 79 licenciandos.

Posteriormente, para o Edital 1/2011, o Pibid/Furg apostou no desenvolvimento do projeto "Ampliando práticas educativas na Educação Básica: diálogos em roda na formação permanente de professores na Furg”. Assim, permitiu a continuidade das licenciaturas do primeiro edital e a inserção de outras três áreas: Educação Física, Geografia e Letras/Francês. Com isso, foram 22 professores supervisores e 116 licenciandos a se envolverem no Pibid. Para o Edital 11/2012, as áreas de licenciatura abrangidas foram: Artes, Letras/Inglês, Letras/Português, Letras/Espanhol, Pedagogia, História, Educação Ambiental e Gestão Escolar.

Posteriormente, houve o Edital 61/2013, e a Furg participou com o projeto institucional "Diálogos em Roda na formação acadêmico-profissional de professores na Furg” (FURG, 2013), o qual contemplou, além da Matemática, as licenciaturas em Física, Biologia, Química, Educação Física, Geografia, Artes, Letras/Francês, Letras/Inglês, Letras/Português, Letras/Espanhol, Pedagogia e História. A inovação esteve na inserção do subprojeto Interdisciplinar e das licenciaturas dos cursos a distância: Ciências e Letras/Espanhol. O objetivo foi compreender a escola e a universidade juntas, integrando professores da educação básica e licenciandos como sujeitos que aprendem em conjunto.

As escolas participantes do Pibid/Furg foram selecionadas por meio da parceria com a Secretaria Municipal de Educação e a Coordenadoria Regional de Educação do município. Ainda, há a ênfase na interlocução entre licenciandos e instituição escolar, sendo que a sistematização das atividades, referente ao Edital $61 / 2013$, ocorreu com a organização dos licenciandos em equipes, as quais frequentavam semanalmente as escolas parceiras para o desenvolvimento de ações e oficinas, visando auxiliar na aprendizagem dos alunos, sob a orientação do professor supervisor. 
Além disso, o professor coordenador de cada subprojeto, os professores supervisores e os licenciandos realizavam rodas de formação na universidade, para discutirem o planejamento de ações e como essas poderiam contribuir efetivamente na aquisição de conhecimentos dos alunos da educação básica. As ações ocorreram, inicialmente, nas turmas dos professores supervisores, todavia, conforme a demanda de outros professores, essas foram estendidas para outras turmas.

Em relação ao Edital 61/2013, o programa possibilitou a formação de 265 licenciandos distribuídos em 16 subprojetos, juntamente com 46 professores da educação básica (CAPES, 2013a), proporcionando a todos um espaço de experiências e amplas oportunidades de estudos, pesquisa e extensão. Colares (2013, p. 24) aponta que:

O PIBID na FURG tem conseguido alcançar seus objetivos, inserindo os licenciandos bolsistas no cotidiano das escolas, e dessa maneira propiciando uma educação de qualidade para todos. Nossas ações, voltadas ao fomento de metodologias e práticas docentes de caráter inovador, com o uso dos recursos da tecnologia da informação e da comunicação, inter-relacionadas com a realidade local das escolas, não visam somente à formação inicial de futuros professores licenciandos, mas também à melhoria para a Educação Básica.

Nesse processo de formação, o Pibid/Furg abarca diferentes dimensões da iniciação à docência, como o princípio da pesquisa de modo articulado e interdisciplinar com todos os subprojetos; o estudo dos documentos nacionais que regulam a formação de professores; a ênfase na escrita em sua função epistêmica na formação docente; a leitura e a discussão de referenciais teóricos educacionais contemporâneos, entre outros. A cada proposta do programa, novas ações foram criadas e intensificadas, um exemplo é a produção semestral de uma narrativa com histórias de sala de aula, que contam experiências da docência. Tais produções foram feitas pelos professores e licenciandos, culminando em cinco edições do Álbum do Pibid Furg, são eles: Galiazzi e Paulitsch (2011); Colares, Galiazzi e Paulitsch (2013); Colares, Galiazzi e Paulitsch (2014); Galiazzi, Colares e Paulitsch (2015); Galiazzi, Colares e Paulitsch (2016).

No Pibid/Furg, em relação ao Edital 61/2013, as rodas de formação foram realizadas semanalmente em cada subprojeto e constituídas por estudantes de licenciaturas, professores coordenadores e professores supervisores. Nelas, os integrantes puderam expor dúvidas, realizar discussões teóricas, fazer reflexões entre a teoria estudada e a prática vivenciada no cotidiano das escolas. Foi na roda do Pibid que os licenciandos elaboraram o planejamento de ações, juntamente com a presença do professor da escola e do professor coordenador, de modo a partilharem experiências, contribuindo para a sua formação e para a formação dos demais. 
Além disso, houve a escrita do relatório anual, em que cada participante fez 0 registro das atividades realizadas ao longo do ano. A escrita reflexiva também fez parte das ações do programa, por meio de um portfólio coletivo construído por cada subprojeto. Nele, os registros foram feitos de maneira rotativa entre os grupos das escolas. Atrelado a isso, foram produzidos trabalhos científicos para a participação de eventos, como a Mostra de Produção Universitária e os Encontros Interinstitucionais de Pibid no Rio Grande do Sul.

A carga horária semanal de licenciandos e professores era organizada considerando: um encontro semanal na Furg, com o grupo de cada subprojeto, a preparação e organização das atividades na escola, um encontro semanal na escola, para desenvolvimento e planejamento das atividades e outras ações específicas de cada subprojeto. No Pibid/Furg, também aconteceram, anualmente, atividades integradoras de socialização das aprendizagens (FURG, 2013), como o Encontro Anual do Pibid, atividades culturais, exposições, oficinas, reuniões de grupos, etc.

Dessa forma, a formação acadêmico-profissional é intensificada pela integração entre teoria e prática e pela aproximação entre a Furg e as escolas atendidas no município. Neste artigo, apresenta-se um recorte do subprojeto Matemática e de um dos grupos do subprojeto Interdisciplinar, referentes ao Edital 61/2013.

\section{Subprojeto Matemática}

As Diretrizes Curriculares Nacionais para os Cursos de Matemática, em seu parecer CNE/CES no 1.302/2001 (BRASIL, 2001), fazem referência às competências e às habilidades que o professor de Matemática deve ter. Dentre essas, destaca-se: a elaboração de propostas com foco no ensino e na aprendizagem de Matemática para a educação básica; a produção de materiais didáticos; e o desenvolvimento de estratégias de ensino que favoreçam a criatividade, a autonomia e a flexibilidade do pensamento matemático dos alunos.

Nesse sentido, as ações desenvolvidas no subprojeto Matemática vêm ao encontro do aperfeiçoamento dessas competências, contribuindo para a inovação da prática de licenciandos e professores da educação básica. Sendo assim, os objetivos centrais que nortearam o subprojeto Matemática do Pibid/Furg, no Edital 61/2013, foram promover a formação acadêmico-profissional de forma a constituir um professor pesquisador e contribuir para qualificar a educação básica, ampliando as possibilidades de aprendizagem dos alunos. Visando atender esses objetivos, a equipe de licenciandos em Matemática participantes do subprojeto era dividida 
para auxiliar nas dificuldades dos alunos e nas necessidades das escolas. Nos encontros semanais, juntamente com professores da educação básica, discutiam-se o planejamento e o desenvolvimento de oficinas conforme o calendário das escolas.

Desse modo, a proposta do subprojeto Matemática teve como proposição o processo investigativo, uma vez que a pesquisa foi considerada um elemento essencial na formação profissional do professor. De acordo com Machado e Pinho (2013, p. 202-203), o subprojeto está "[...] efetivando um trabalho coletivo, que procura desenvolver a autonomia intelectual dos licenciandos, [...] e assim, a pesquisa permeia todo o fazer metodológico". Além disso, as autoras argumentam que o diálogo está presente nas rodas de conversas.

Os questionamentos iniciam-se já na fase de imersão gradativa no ambiente escolar, licenciandos, professor da universidade e professor supervisor (professor da escola) em intenso diálogo, a partir das observações e constatações começam a problematizar seus modos de agir. [...]. Os diálogos permeados em nossos encontros constituem rodas de conversas, conferindo-se a legitimidade da articulação dos conhecimentos teóricos com a prática desenvolvida em sala de aula (MACHADO; PINHO, 2013, p. 203).

Ao encontro desse processo formativo e coletivo, o subprojeto Matemática sempre preconizou suprimir os preconceitos e as relações hierárquicas. Assim, todos aprendem, juntos, diferentes modos de avaliação, de comportamentos e de outros aspectos presentes na realidade escolar e no ensino da Matemática. A iniciação na escola realiza-se com visitas orientadas pelo professor supervisor. Ao conhecer o ambiente escolar, acredita-se no favorecimento das capacidades de reflexão, cooperação e participação, de maneira que os licenciandos possam intervir em uma realidade da qual estão fazendo parte (MACHADO; PINHO, 2013).

Além disso, na sexta edição do Pibid/Furg, houve o desenvolvimento de uma proposta de atividades denominada "Movimentando-se com a Escrita" (ANTIQUEIRA; MACHADO, 2017), realizada, semanalmente, com as demais atividades do subprojeto, no período de outubro de 2014 a dezembro de 2015. Foram desenvolvidas sete práticas envolvendo a produção de diferentes gêneros textuais e temáticas articuladas ao ensino da Matemática e a conteúdos da educação básica. Ainda, a proposta desenvolvida propiciou, além da prática da linguagem escrita, atividades de leitura e pesquisa, análises de artigos, momentos de diálogo com e entre os participantes.

No que se refere a outras ações desenvolvidas, o subprojeto Matemática, até o encerramento do Edital 61/2013, contemplou atividades específicas como: planejamento de atividades extraclasse, de acordo com as dificuldades dos estudantes da 
educação básica; articulação dos conteúdos de maneira interdisciplinar; desenvolvimento de material concreto e virtual relacionado aos conteúdos escolares; e elaboração e desenvolvimento de oficinas para alunos da educação básica. Machado e Pinho (2013, p. 210) sinalizam que "[...] alternativas são criadas a fim de contemplar um trabalho de exploração e/ou de aplicação de conceitos matemáticos”.

A cada oficina desenvolvida, foram elaborados roteiros de sala de aula, constando a descrição das atividades, sua caracterização e a escrita reflexiva individual de cada integrante. Ainda, a plataforma Moodle foi utilizada como meio de comunicação entre licenciandos, professores supervisores e coordenadores, servindo também para o registro das atividades desenvolvidas ao longo do subprojeto. Semanalmente, aconteciam as rodas de formação do Pibid Matemática na universidade, nas quais eram realizadas pesquisas, estudos e leituras, de modo a subsidiar a elaboração de ações para atender às demandas das escolas levantadas pelo professor supervisor. Conjuntamente, eram discutidas metodologias para o ensino da Matemática.

Uma das oficinas elaboradas no subprojeto Matemática do Pibid/Furg foi denominada de "Boliche Matemático" (RODRIGUES et al., 2014), desenvolvida por três licenciandos, em uma turma de $7^{\circ}$ ano do ensino fundamental, sob a orientação da professora supervisora. O objetivo foi auxiliar nas operações matemáticas envolvendo as regras de sinais. Sobre essa atividade, os licenciandos ressaltam que "[...] os alunos compreenderam melhor as regras de sinais nas operações, trabalhando unidos nas suas equipes e ajudando os demais colegas. Eles gostaram e participaram não se dispersando com nenhuma outra movimentação ao redor" (RODRIGUES et al., 2014, p. 3).

Outra oficina foi a "Trilha das Frações" (ROZA; XAVIER, 2014), desenvolvida com 45 alunos do $6^{\circ}$ ano do ensino fundamental, com o objetivo de auxiliar na compreensão de multiplicação e divisão de frações. Os alunos tinham que ir avançando casas da trilha conforme acertavam questões envolvendo frações, e isso foi fundamental para atrair a atenção deles. As autoras da oficina afirmam que: “Trabalhamos [...] sem que o aluno sinta a pressão de aprender, notando assim que as formas de aprender são diversas, logo, instigamos a curiosidade deles e atraímos a atenção para a aula" (ROZA; XAVIER, 2014, p. 2).

Como parte desse conjunto de ações, a oficina "Explorando a Divisibilidade através do Jogo da Memória" (SOARES et al., 2014) foi desenvolvida com alunos do $6^{\circ}$ ano do ensino fundamental e consistiu em quatro momentos, nos quais os estudantes puderam: refletir, discutir, pesquisar, interpretar, escrever e exercitar. 
Os autores da oficina observam que "[...] os estudantes trabalhando coletivamente, [...] resumiram e reescreveram, com suas palavras, as explicações referentes a cada critério de divisibilidade, buscando dessa forma aproximá-las a sua realidade" (SOARES et al., 2014, p. 2). Além disso, os estudantes desenvolveram habilidades e técnicas para a resolução das contas, reconhecendo e relacionando os critérios de divisibilidade aos seus algarismos correspondentes.

Outras estratégias de ensino também foram realizadas pelos licenciandos. Ressalta-se que o processo de elaboração, planejamento e execução das oficinas propicia aos envolvidos um conhecimento produzido na ação e sobre a ação de ensinar. De certa forma, isso contribui para a formação de um profissional reflexivo e crítico de suas práticas (PIMENTA; GHEDIN, 2012).

No subprojeto Matemática do Pibid/Furg, licenciandos e professores tornam-se sujeitos do aprender, exercendo os papéis de questionadores e investigadores. Isso é reforçado pela ideia de Brandão (2005, p. 90) de que, “[...] numa comunidade aprendente, todos têm algo a ouvir e algo a dizer. Algo a aprender e algo a ensinar". Ainda, o autor considera uma comunidade aprendente como: "Lugares de trocas e de reciprocidades de saberes, mas também de vidas e de afetos, onde a aula expositiva pode ser cada vez mais convertida no círculo de diálogos" (2005, p. 90). É nesse espaço de formação que professores e licenciandos podem agir com criatividade, realizar trabalhos individuais e coletivos, bem como experienciar o ambiente escolar.

\section{Subprojeto Interdisciplinar}

Um dos subprojetos do Pibid/Furg, referente ao Edital 61/2013, foi o Interdisciplinar, denominado "Abordagens Temáticas para Sociedades Sustentáveis". Este foi desenvolvido de forma a articular a formação acadêmico-profissional dos professores com as diferentes áreas do conhecimento. As ações tiveram como foco a sustentabilidade, o contexto sociocultural e as abordagens temáticas interdisciplinares e transversais desenvolvidas nas escolas. Tudo isso com base no planejamento integrado, no aprofundamento teórico e em discussões, no princípio da pesquisa e nas rodas de formação como processo de constituir-se professor.

O subprojeto Interdisciplinar era dividido em quatro grupos. Neste artigo, são apresentadas algumas ações de um desses grupos, referentes ao período de 2014 a 2015. Fizeram parte da equipe 15 acadêmicos oriundos de diferentes licenciaturas, três professoras supervisoras, que foram coordenadoras pedagógicas de três 
escolas e responsáveis, cada uma, por cinco licenciandos no desenvolvimento das atividades que visavam atender às necessidades das escolas.

O subprojeto Interdisciplinar teve como objetivo compreender e discutir sobre interdisciplinaridade e formação de professores. Para isso, o grupo realizava leituras referentes a essas temáticas, com a intenção de se aprofundar teoricamente e realizar produções de resenhas e escritas reflexivas, bem como discussões e postagens na Plataforma Moodle. Além dessas práticas de leitura e escrita, ressalta-se a formação acadêmico-profissional numa perspectiva interdisciplinar, a partir da inserção de licenciandos nas escolas, com a mediação das professoras supervisoras, para o processo de reconhecimento e construção de um diagnóstico acerca do contexto social. Para isso, foram realizadas visitas nas salas de aula, observações sobre a estrutura, reuniões com a equipe diretiva, conversas com professores e funcionários das escolas.

Com base nesse diagnóstico, diversos projetos interdisciplinares e práticas pedagógicas foram elaborados e desenvolvidos nas escolas parceiras, como o projeto "O uso da horta na produção de alimentos", com práticas de confecção de espantalho, elaboração de tabelas, aulas de culinária com aproveitamento de alimentos, paródias e oficinas. Também foi desenvolvido o projeto "Trabalhando a História da Escola", no qual os licenciandos realizaram entrevistas, fizeram levantamento de material bibliográfico e de fotos da escola e coletaram depoimentos, para posteriormente construírem o memorial da escola.

Diante do exposto, constata-se que o Pibid aposta na formação de professores, oportunizando a cada licenciando o seu reconhecimento como futuro professor e o pertencimento ao seu espaço de atuação. O subprojeto Interdisciplinar busca relacionar esta formação com as vivências que são adquiridas na construção e aplicação de projetos interdisciplinares, apontando as dificuldades e os prazeres que envolvem a prática docente, além do entrelaçamento dos projetos com as disciplinas das escolas.

\section{Considerações finais}

As atividades desenvolvidas no Pibid/Furg são sustentadas a partir da formação de professores em comunidades aprendentes, todos ensinam e todos aprendem, num processo de interação constante. Por esta razão, o desenvolvimento do Pibid na instituição causou impactos positivos, desde o primeiro edital, na formação de centenas de licenciandos, de aproximadamente 50 professores de escolas da educa- 
ção básica do município de Rio Grande, RS, e de professores da universidade. Isso aconteceu pela articulação entre os 16 cursos de licenciatura e o ambiente escolar, o qual envolve a escola, a família e a comunidade.

As experiências metodológicas foram divulgadas em diversos trabalhos apresentados por licenciandos, publicados em eventos como o Encontro de Investigação na Escola e a Mostra de Produção Universitária, além dos diálogos estabelecidos com outras áreas e eventos específicos de cada área. Além disso, houve o envolvimento dos participantes em pesquisas de trabalhos de conclusão de cursos, dissertações e teses; como exemplo, tem-se a tese de Antiqueira (2018).

Quanto à elaboração de materiais didáticos, várias oficinas com atividades diversificadas e integradas ao currículo foram desenvolvidas para alunos das escolas públicas, o que possibilitou aos licenciandos o conhecimento do processo de aprendizagem e da realidade dessas instituições. Outros impactos se referem à sensibilização para as questões ambientais na escola, em casa e na comunidade e à melhora nas produções textuais dos alunos.

Em suma, o Pibid desenvolvido no âmbito da Furg colabora para promover uma formação acadêmico-profissional por meio da ação-reflexão-ação, articulando teoria e prática, desde a sala de aula até os cursos de licenciatura. O recorte dos subprojetos apresentados neste artigo evidenciou que os licenciandos se envolveram em práticas articuladas com a realidade das escolas e, consequentemente, comprometeram-se com os desafios inerentes ao dia a dia da sala de aula.

\section{Referências}

ANTIQUEIRA, L. O aprender com e sobre a linguagem escrita no Pibid Matemática: sentidos construídos pelos professores de Matemática em formação acadêmico-profissional. 2018. 231f. Tese (Doutorado em Educação em Ciências) - Programa de Pós-Graduação em Educação em Ciências, Universidade Federal do Rio Grande, Rio Grande, 2018. Disponível em: <https://argo. furg.br/?BDTD11903>. Acesso em: 26 set. 2018.

ANTIQUEIRA, L.; MACHADO, C. Movimentando-se com a escrita: uma proposta com professores em formação. In: CEBREIROS, M. et al. (Org.). La enseñanza de las ciencias en el actual contexto educativo. Ourense, Espanha: Educacíon, 2017. v. 1. p. 605-610.

ARAÚJO, E. S.; MOURA, M. O. Contribuições da teoria histórico-cultural à pesquisa qualitativa sobre formação docente. In: PIMENTA, S. G.; FRANCO, M. A. S. (Org.). Pesquisa em educação: possibilidades investigativas/formativas da pesquisa-ação. 2. ed. São Paulo: Loyola, 2012. v. 1. p. $75-101$.

BARBOSA, M. V.; DANTAS, F. B. A. Reflexões sobre a formação inicial de professores no Pibid. Campinas: Mercado de Letras, 2014. 
BERNARDES, A.; DINIZ-PEREIRA, J. E. Escolhas, percursos e trajetórias de formação: reflexões sobre a aprendizagem profissional da docência de professores iniciantes de geografia. Revista Olhar de professor, Ponta Grossa: UEPG, v. 15, n. 2, p. 251-267, jul. 2012.

BRANDÃO, C. R. Comunidade aprendente. In: FERRARO JR., L. (Org.). Encontros e Caminhos: formação de educadoras (es) ambientais e coletivos educadores. Brasília, DF: MMA, 2005. p. 83-92.

BRASIL. Conselho Nacional de Educação. Parecer CNE/CES 1302/2001 - Institui Diretrizes Curriculares Nacionais para os cursos de Matemática Bacharelado e Licenciatura. Brasília, DF: CES, 2001. Disponível em: <http://portal.mec.gov.br/cne/arquivos/pdf/CES13022.pdf>. Acesso em: 17 jan. 2015.

COORDENAÇÃO DE APERFEIÇOAMENTO DE PESSOAL DE NÍVEL SUPERIOR. Planilha de projetos e subprojetos Pibid - edital 2013. Brasília, DF: Capes, 2013a. Disponível em: <http:// www.capes.gov.br/educacao-basica/capespibid/pibid>. Acesso em: 23 nov. 2015.

Diretoria de Formação de Professores da Educação Básica. Relatório de Gestão - Pibid, 2009-2011. Brasília, DF: Capes, 2011. Disponível em: <http://www.capes.gov.br/educacao-basica/ capespibid/relatorios-e-dados>. Acesso em: 18 jan. 2014.

. Diretoria de Formação de Professores da Educação Básica. Relatório de Gestão - Pibid, 2009-2013. Brasília, DF: Capes, 2013b. Disponível em: <https://www.capes.gov.br/images/stories/download/bolsas/2562014-relatrorio-DEB-2013-web.pdf.>. Acesso em: 12 jan. 2015.

COLARES, I. O Pibid na Furg. In: GALIAZZI, M. do C.; COLARES, I. Comunidades aprendentes de professores: o Pibid na Furg. Ijuí: Unijuí, 2013. p. 11-24.

COlARES, I.; GAliAZZI, M. C.; PAUliTSCH, V. S. (Org.). Álbum do Pibid Furg. 2. ed. Rio Grande: Editora da Furg, 2013.

COlARES, I.; GAliAZZI, M. C.; PAUlitsCH, V. S. (Org.). Álbum do Pibid Furg. 3. ed. Rio Grande: Editora da FURG, 2014.

DINIZ-PEREIRA, J. E. A formação acadêmico-profissional: Compartilhando responsabilidades entre as universidades e escolas. In: ENCONTRO NACIONAL DE DIDÁTICA E PRÁTICAS DE ENSINO, 14, 2008, Porto Alegre. Anais... Porto Alegre: PUCRS, 2008. p. 253-267.

A prática como componente curricular na formação de professores. Educação, Santa Maria: Lapedoc, v. 36, n. 2, p. 203-218, maio/ago. 2011.

GALIAZZI, M.; COLARES, I. (Org.). Comunidades aprendentes de professores: o Pibid na Furg. Ijuí: Unijuí, 2013.

GALIAZZI, M. C.; MORAES, R. Comunidades aprendentes de professores: uma proposta de formação no Pibid-Furg. In: GALIAZZI, M. C.; COLARES, I. (Org.). Comunidades aprendentes de professores: o Pibid na Furg. Ijuí: Unijuí, 2013. p. 259-275.

GALIAZZI, M. C.; PAULITSCH, V. S. (Org.). Álbum do Pibid Furg. Rio Grande: Editora da Furg, 2011.

GALIAZZI, M. C.; COLARES, I. G.; PAULITSCH, V. S. (Org.). Álbum do Pibid Furg 4. Rio Grande: Editora da Furg, 2015. 
GALIAZZI, M. C.; COLARES, I. G.; PAULITSCH, V. S. (Org.). Álbum do Pibid Furg 5. Rio Grande: Editora da Furg, 2016.

GALIAZZI, M. C. et al. Cirandar: rumo a comunidades aprendentes na formação acadêmico-profissional em roda. In: GALIAZZI, M. C. (Org.). Cirandar: rodas de investigação desde a escola. São Leopoldo: Oikos, 2013. p. 157-168.

GATTI, B. et al. Um estudo avaliativo do Programa Institucional de Bolsas de Iniciação à Docência (Pibid). São Paulo: Fundação Carlos Chagas, 2014. Disponível em: <http://www.capes.gov.br/ images/stories/download/bolsas/24112014-pibid-arquivoAnexado.pdf>. Acesso em: 19 maio 2016.

LIMA, M. S.; GOMES, M. O. Redimensionando o papel dos profissionais da educação: algumas considerações. In: PIMENTA, S. G.; GHEDIN, E. (Org.). Professor reflexivo no Brasil: gênese e crítica de um conceito. São Paulo: Cortez, 2012. p. 186-214.

MACHADO, C.; PINHO, D. Percepções acerca do Pibid Matemática Furg. In: GALIAZZI, M. C.; COLARES, I. (Org.). Comunidades aprendentes de professores: o Pibid na Furg. Ijuí: Unijuí, 2013. p. 201-216.

PIMENTA, S. G.; GHEDIN, E. Professor reflexivo no Brasil: gênese e crítica de um conceito. São Paulo: Cortez, 2012.

REICHERT, I.; MOANA, M.; LIMA, J. Do diálogo entre escola e universidade: o Pibid Feevale em seus primeiros passos e reflexões. Novo Hamburgo: Feevale, 2014.

ROCHA, J.; ZIBETTI, M. Programa de Bolsas de Iniciação à Docência: análise sobre uma política de formação de professores. In: PACÍFICO, J.; BUENO, J.; SOUZA, A. (Org.). Formação docente na universidade em interface com a educação básica: ultrapassar limites, criar possibilidades. Florianópolis: Pandion, 2014. p. 129-154.

RODRIGUES, D. et al. Campeonato de Boliche Matemático. In: MOSTRA DE PRODUÇÃO UNIVERSITÁRIA, 13. Anais... Rio Grande: Furg, 2014. Disponível em <http://propesp.tmp.furg.br/ anaismpu/cd2014/index.html>. Acesso em: 22 jun. 2015.

ROZA, F.; XAVIER, R. Trilha das Frações. In: GALIAZZI, M. C. (Org.). Cirandar: rodas de investigação desde a escola. Rio Grande: Editora da Furg, 2014. p. 109-112.

SOARES, M. et al. Explorando a divisibilidade através do jogo da Memória. In: MOSTRA DE PRODUÇÃO UNIVERSITÁRIA, 13. Anais... Rio Grande: Furg, 2014. Disponível em <http://propesp.tmp.furg.br/anaismpu/cd2014/index.html>. Acesso em: 22 jun. 2015.

UNIVERSIDADE FEDERAL DO RIO GRANDE. Projeto Institucional Pibid: "Diálogos em Roda" na formação acadêmico - profissional de professores na Furg. Anexo I. Edital nº 061/2013/Capes - Pibid. 2013. Disponível em: <http://www.sinsc.furg.br/detalheseventos/63>. Acesso em: 22 jun. 2015. 